\title{
Epidemiology, clinical presentation, and evaluation of upper-tract urothelial carcinoma
}

\author{
Firas G. Petros \\ Department of Urology, The University of Toledo Medical Center, College of Medicine and Life Sciences, Toledo, Ohio, USA \\ Correspondence to: Firas G. Petros, MD. Department of Urology, The University of Toledo Medical Center, 3000 Arlington Ave., Mail Stop 1091, \\ Toledo, Ohio 43614-2598, USA. Email: firas.petros@utoledo.edu.
}

\begin{abstract}
An overview of epidemiological pattern of upper tract urothelial carcinoma (UTUC), including outcome of UTUC over past decades as well as factors responsible for observed epidemiological changes was performed. Gender and racial disparities influencing incidence of UTUC were reviewed. The incidence of multifocal urothelial carcinoma and relation of UTUC to urothelial carcinoma of bladder were examined.
\end{abstract}

Keywords: Upper tract urothelial carcinoma (UTUC); epidemiology; incidence; clinical presentation; ureteral cancer; renal pelvic cancer

Submitted Oct 14, 2019. Accepted for publication Nov 18, 2019.

doi: $10.21037 /$ tau.2019.11.22

View this article at: http://dx.doi.org/10.21037/tau.2019.11.22

\section{Epidemiology and incidence of upper tract urothelial carcinoma (UTUC)}

\section{Epidemiology}

UTUC is defined as malignant changes to the urothelial cells lining the urinary tract anywhere from renal calyces, renal pelvis, or ureter down to ureteral orifice. Although 61,700 estimated new cases of bladder cancer are diagnosed in 2019 in the United States (1), UTUC is still relatively an uncommon type of genitourinary malignancy representing $5 \%$ of urothelial cancers and less than $10 \%$ of renal tumors (2). It is difficult to determine the exact incidence of UTUC because often renal pelvis and ureteral malignancies are reported combined with renal cell carcinoma in a single category as renal tumors (1).

The estimated annual incidence of UTUC in the Western countries is up to 2 new cases per 100,000 personyears $(3,4)$. Urothelial pelvicalyceal tumors are diagnosed as twice as urothelial carcinoma of the ureter (5). The epidemiological patterns of UTUC over a period of 30 years was analyzed using a large population-based cohort from Surveillance, Epidemiology, and End Results (SEER) in the United States (2). Raman et al. showed a minimal decrease in incidence of renal pelvicalyceal tumors from 1.19 to 1.15 cases per 100,000 person-years compared to an increase in incidence of ureteral tumors from 0.69 to 0.91 cases per 100,000 person-years accounting for an increase in overall incidence of UTUC from 1.88 to 2.06 cases per 100,000 person-years (2). UTUC have a peak incidence between ages $70-90$ years $(3,6)$. The mean age at diagnosis has increased over the past 30 years with an overall increase of 5 years from 68 to 73 years (2).

The outcome of UTUC is closely associated with the stage of disease at presentation (5). At time of diagnosis, approximately $40-50 \%$ of patients have non-muscle invasive UTUC (pTa/T1), 50-60\% of patients present with muscleinvasive or non-organ confined disease $(\mathrm{P} \geq \mathrm{T} 2)$, and up to $25 \%$ of patients presents with metastasis at diagnosis $(5,7,8)$. Over a 30-year period, the incidence of in situ tumors have increased from $7.2 \%$ to $31 \%$, compared to significant reduction in incidence of local tumors over the same period (50.4\% to $23.4 \%, \mathrm{P}<0.001$ ). Remarkably, regional UTUC was noted to significantly increase by $2.6 \%(\mathrm{P}=0.003)$, whereas the incidence of distant UTUC did not differ over time $(\mathrm{P}=0.12)(2)$.

There have been multiple factors influenced the incidence of UTUC and observed changes in epidemiological patterns of the disease over the past decades. Earlier detection of smaller tumors using advanced cross-sectional imaging technologies such as computed 
tomography or magnetic resonance imaging significantly outperformed intravenous pyelography used in the past (9). The pivotal and revolutionary advancement in endoscopic technology with introduction of small-diameter flexible and digital ureteroscopes with improved functional deflection, and innovation of various types of biopsy forceps and baskets allowed for a better-quality biopsy and thus improved histologic detection of early-stage tumors (10). Ultimately, advancement in bladder cancer diagnosis and treatment led to boosted cancer-specific survival and thus an increase in incidence of upper-tract disease shedding the light on the natural history of UTUC.

\section{Gender}

Studies have shown that UTUC develops 2-3 times more commonly in men than women (6-8). Conclusive evidence of gender influence on outcome of patients with UTUC is currently lacking, despite men seems to have a higher incidence of disease, whereas survival outcomes might be independent of gender. Over the past decades, Raman et al found that male gender was associated with worse overall survival $(\mathrm{P}<0.005)$, with $7 \%(64 \%$ vs. $57 \%)$ and $5 \%(52$ vs. $47 \%$ ) at 3 and 5 years, respectively compared to female gender (2). However, multi-institutional retrospective studies found no association between pathologic features, disease recurrence, or cancer-specific mortality and gender of patients with UTUC treated with radical nephroureterectomy (RNU) $(6,11)$. On the contrary, one SEER-based study, found female patients having higher cancer-specific mortality rate, but this finding lost significance in their multivariable competing-risks regression model (12). Another study from Austria described women having worst survival outcomes in advanced stages (13). However, a recent large hospitalbased cancer registry study from an endemic area in Taiwan reported female patients had significantly improved survival outcomes compared to their male counterparts, which were mostly driven by the non-muscle-invasive disease (14). Taken altogether, although differences in survival based on gender are noticeable, it is difficult to pinpoint exact etiology as to whether this is because of biology of disease or the presence of associated comorbid conditions in male patients.

\section{Race}

Similar to other urologic malignancies, racial disparities have been noticed in UTUC with the vast majority patients affected by UTUC are Caucasians (80-90\%)
$(2,15,16)$. However, over the past decades, the incidence of UTUC has deceased among white patients $(92.6 \%$ to $88.3 \%, \mathrm{P}<0.001)$, while incidence has increased among black patients $(3.4 \%$ to $4.3 \%, \mathrm{P}=0.09)$ and other ethnicities (4.0\% to $7.5 \%, \mathrm{P}<0.001$ ) (2). Race-associated survival outcome differences were also observed in populationbased study with black non-Hispanic patients having 30\% higher mortality compared to other radical groups (2). In contrast, an international multi-institutional study found no effect of race or ethnicity on recurrence or cancerrelated death (16). As such, different ethnicities have different clinico-pathologic features of their UTUC, yet race has not been shown to be an independent predictor for survival (3).

\section{Relation of UTUC to urothelial carcinoma of bladder}

Urothelial carcinoma is inherently multifocal disease with a tendency for recurrence after initial treatment. These disease characteristics make urothelial carcinoma one of the most perplexing cancer to treat including synchronous and/or metachronous tumors as well as multifocality within the urothelium, whether involving upper tract, bladder or urethra. There are 2 proposed theories for development of multifocal synchronous and/ or metachronous tumors. The monoclonality hypothesis describes occurrence of multifocal tumor as a consequence of a single genetically abnormal cell spreading throughout the urothelium. Whereas, field cancerization effect causes an independent development of synchronous or metachronous nonrelated tumors at different location within urothelial tract $(17,18)$. Spread of malignant cells has been described via either intraluminal seeding and/or intraepithelial migration. Therefore, often it is difficult to establish origin of these lesions whether represent seeding sites from same primary tumor or represent true second primary "de novo" lesions.

\section{Synchronous urothelial carcinoma of bladder and UTUC}

The incidence of concomitant bladder and upper urothelial tract tumors is $8-17 \%(3,19)$. However, contralateral recurrence of UTUC has been report to be up to $6 \%$, with multifocal UTUC in one third of cases $(3,20)$. Synchronous bilateral UTUC are also rare at presentation and $80 \%$ of patients in one population-based study had urothelial carcinoma of bladder diagnosed either before or following diagnosis of UTUC (21). 
Primary urothelial carcinoma of bladder followed by metachronous UTUC

The incidence of UTUC ranges from $0.7 \%$ to $1.7 \%$ with a median of 4.1 years following diagnosis of urothelial carcinoma of bladder $(22,23)$. The incidence of UTUC after radical cystectomy ranged from $0.75 \%$ to $6.4 \%$ in a large meta-analysis involving 27 studies as early as 2.4 to 164 months following cystectomy $(24,25)$. Prior history of muscle-invasive urothelial carcinoma of bladder was shown to be significantly associated with an increased risk of UTUC recurrence and cancer-specific death (26). In another multi-institutional study primary carcinoma in situ of bladder was found to be an independent predictor of UTUC recurrence and death after RNU (27). At time of diagnosis or treatment with RNU, approximately $25 \%$ of UTUC patients previously had non-muscle invasive urothelial carcinoma of bladder $(7,8)$.

\section{Primary UTUC followed by metachronous urothelial carcinoma of bladder}

The incidence of urothelial carcinoma of bladder following treatment of UTUC is approximately $15 \%$ to $50 \%(19,28)$ with intravesical recurrence represents the most common site of recurrence. Metachronous bladder tumors usually occur within an average of 1-2 years after treatment of primary UTUC (28-31). Approach to RNU did not appear to influence risk of bladder recurrence (32) or overall survival $(33,34)$.

\section{Diagnosis: clinical presentation and evaluation}

\section{Clinical presentation}

The most common presenting symptom in two third of patients with UTUC is either gross or microscopic hematuria (35) whereas $25 \%$ of patients present with flank pain secondary to obstruction of either the kidney and/or the ureter by upper tract tumor (3). Findings of hydronephrosis on preoperative imaging can be seen in $37 \%$ to $80 \%$ of patients. Studies have suggested the presence of preoperative hydronephrosis is prognostic indicator for advanced disease and this information may impact decision for neoadjuvant chemotherapy as well as extent of radical resection $(36,37)$. Less commonly, patients may present with a flank mass (3) and rarely, UTUC found incidentally on imaging and these patients are asymptomatic at diagnosis. The presence of constitutional symptoms of weight loss, anorexia, fatigue, malaise, fever, night sweats and cough associating UTUC should trigger a thorough metastatic workup since these symptoms predict worse outcome (3).

\section{Clinical evaluation}

The clinical assessment of patients thought to have UTUC should start with history evaluating risk factors and physical examination including abdominal exam. Workup including microscopic urinalysis to detect microscopic hematuria ruling out concomitant urinary tract infection, urine cytology, laboratory tests including hemoglobin level and renal function, and upper tract axial imaging with CT or MR urography, or renal ultrasound, CT/MR without contrast and retrograde pyelography if iodinated or gadolinium-based contrast are contraindicated. Nuclear renogram might also be obtained if indicated. Ultimately, cystoscopy, ureteroscopy with biopsy can be pursued.

\section{Acknowledgments}

Funding: None.

\section{Footnote}

Provenance and Peer Review: This article was commissioned by the Guest Editors (John J. Knoedler and Jay D. Raman) for the series "Upper-Tract Urothelial Carcinoma: Current State and Future Directions" published in Translational Andrology and Urology. The article was sent for external peer review organized by the Guest Editors and the editorial office.

Conflicts of Interest: The author has completed the ICMJE uniform disclosure form (available at http://dx.doi. org/10.21037/tau.2019.11.22). The series "UpperTract Urothelial Carcinoma: Current State and Future Directions" was commissioned by the editorial office without any funding or sponsorship. The author has no other conflicts of interest to declare.

Ethical Statement: The author is accountable for all aspects of the work in ensuring that questions related to the accuracy or integrity of any part of the work are appropriately investigated and resolved.

Open Access Statement: This is an Open Access article distributed in accordance with the Creative Commons Attribution-NonCommercial-NoDerivs 4.0 International 
License (CC BY-NC-ND 4.0), which permits the noncommercial replication and distribution of the article with the strict proviso that no changes or edits are made and the original work is properly cited (including links to both the formal publication through the relevant DOI and the license). See: https://creativecommons.org/licenses/by-nc-nd/4.0/.

\section{References}

1. Siegel RL, Miller KD, Jemal A. Cancer statistics, 2019. CA Cancer J Clin 2019;69:7-34.

2. Raman JD, Messer J, Sielatycki JA, et al. Incidence and survival of patients with carcinoma of the ureter and renal pelvis in the USA, 1973-2005. BJU Int 2011;107:1059-64.

3. Roupret M, Babjuk M, Comperat E, et al. European Association of Urology Guidelines on Upper Urinary Tract Urothelial Carcinoma: 2017 Update. Eur Urol 2018;73:111-22.

4. Munoz JJ, Ellison LM. Upper tract urothelial neoplasms: incidence and survival during the last 2 decades. J Urol 2000;164:1523-5.

5. Rink M, Ehdaie B, Cha EK, et al. Stage-specific impact of tumor location on oncologic outcomes in patients with upper and lower tract urothelial carcinoma following radical surgery. Eur Urol 2012;62:677-84.

6. Shariat SF, Favaretto RL, Gupta A, et al. Gender differences in radical nephroureterectomy for upper tract urothelial carcinoma. World J Urol 2011;29:481-6.

7. Margulis V, Shariat SF, Matin SF, et al. Outcomes of radical nephroureterectomy: a series from the Upper Tract Urothelial Carcinoma Collaboration. Cancer 2009;115:1224-33.

8. Cha EK, Shariat SF, Kormaksson M, et al. Predicting clinical outcomes after radical nephroureterectomy for upper tract urothelial carcinoma. Eur Urol 2012;61:818-25.

9. Chlapoutakis K, Theocharopoulos N, Yarmenitis S, et al. Performance of computed tomographic urography in diagnosis of upper urinary tract urothelial carcinoma, in patients presenting with hematuria: Systematic review and meta-analysis. Eur J Radiol 2010;73:334-8.

10. Andonian S, Okeke Z, Smith AD. Digital ureteroscopy: the next step. J Endourol 2008;22:603-6.

11. Fernandez MI, Shariat SF, Margulis V, et al. Evidence-based sex-related outcomes after radical nephroureterectomy for upper tract urothelial carcinoma: results of large multicenter study. Urology 2009;73:142-6.

12. Lughezzani G, Sun M, Perrotte P, et al. Gender-related differences in patients with stage I to III upper tract urothelial carcinoma: results from the Surveillance, Epidemiology, and End Results database. Urology 2010;75:321-7.

13. Mohamad Al-Ali B, Madersbacher S, Zielonke N, et al. Impact of gender on tumor stage and survival of upper urinary tract urothelial cancer : A population-based study. Wien Klin Wochenschr 2017;129:385-90.

14. Huang CC, Su YL, Luo HL, et al. Gender Is a Significant Prognostic Factor for Upper Tract Urothelial Carcinoma: A Large Hospital-Based Cancer Registry Study in an Endemic Area. Front Oncol 2019;9:157.

15. Petros FG, Qiao W, Singla N, et al. Preoperative multiplex nomogram for prediction of high-risk nonorgan-confined upper-tract urothelial carcinoma. Urol Oncol 2019;37:292.e1-9.

16. Matsumoto K, Novara G, Gupta A, et al. Racial differences in the outcome of patients with urothelial carcinoma of the upper urinary tract: an international study. BJU Int 2011;108:E304-9.

17. Duggan BJ, Gray SB, McKnight JJ, et al. Oligoclonality in bladder cancer: the implication for molecular therapies. J Urol 2004;171:419-25.

18. Hafner C, Knuechel R, Stoehr R, et al. Clonality of multifocal urothelial carcinomas: 10 years of molecular genetic studies. Int J Cancer 2002;101:1-6.

19. Azemar MD, Comperat E, Richard F, et al. Bladder recurrence after surgery for upper urinary tract urothelial cell carcinoma: frequency, risk factors, and surveillance. Urol Oncol 2011;29:130-6.

20. Li WM, Shen JT, Li CC, et al. Oncologic outcomes following three different approaches to the distal ureter and bladder cuff in nephroureterectomy for primary upper urinary tract urothelial carcinoma. Eur Urol 2010;57:963-9.

21. Holmang S, Johansson SL. Synchronous bilateral ureteral and renal pelvic carcinomas: incidence, etiology, treatment and outcome. Cancer 2004;101:741-7.

22. Oldbring J, Glifberg I, Mikulowski P, et al. Carcinoma of the renal pelvis and ureter following bladder carcinoma: frequency, risk factors and clinicopathological findings. J Urol 1989;141:1311-3.

23. Rabbani F, Perrotti M, Russo P, et al. Upper-tract tumors after an initial diagnosis of bladder cancer: argument for long-term surveillance. J Clin Oncol 2001;19:94-100.

24. Picozzi S, Ricci C, Gaeta M, et al. Upper urinary tract recurrence following radical cystectomy for bladder cancer: a meta-analysis on 13,185 patients. J Urol 2012;188:2046-54. 
25. Tran W, Serio AM, Raj GV, et al. Longitudinal risk of upper tract recurrence following radical cystectomy for urothelial cancer and the potential implications for longterm surveillance. J Urol 2008;179:96-100.

26. Nuhn P, Novara G, Seitz C, et al. Prognostic value of prior history of urothelial carcinoma of the bladder in patients with upper urinary tract urothelial carcinoma: results from a retrospective multicenter study. World J Urol 2015;33:1005-13.

27. Youssef RF, Shariat SF, Lotan Y, et al. Prognostic effect of urinary bladder carcinoma in situ on clinical outcome of subsequent upper tract urothelial carcinoma. Urology 2011;77:861-6.

28. Petros FG, Li R, Matin SF. Endoscopic Approaches to Upper Tract Urothelial Carcinoma. Urol Clin North Am 2018;45:267-86.

29. Berger A, Haber GP, Kamoi K, et al. Laparoscopic radical nephroureterectomy for upper tract transitional cell carcinoma: oncological outcomes at 7 years. J Urol 2008;180:849-54; discussion 54.

30. Raman JD, Ng CK, Boorjian SA, et al. Bladder cancer after managing upper urinary tract transitional cell carcinoma: predictive factors and pathology. BJU Int 2005;96:1031-5.

31. Matsui Y, Utsunomiya N, Ichioka K, et al. Risk factors for subsequent development of bladder cancer after primary transitional cell carcinoma of the upper urinary tract.

Cite this article as: Petros FG. Epidemiology, clinical presentation, and evaluation of upper-tract urothelial carcinoma. Transl Androl Urol 2020;9(4):1794-1798. doi: 10.21037/tau.2019.11.22
Urology 2005;65:279-83.

32. Roupret M, Hupertan V, Sanderson KM, et al. Oncologic control after open or laparoscopic nephroureterectomy for upper urinary tract transitional cell carcinoma: a single center experience. Urology 2007;69:656-61.

33. Rodriguez JF, Packiam VT, Boysen WR, et al. Utilization and Outcomes of Nephroureterectomy for Upper Tract Urothelial Carcinoma by Surgical Approach. J Endourol 2017;31:661-5.

34. Tinay I, Gelpi-Hammerschmidt F, Leow JJ, et al. Trends in utilisation, perioperative outcomes, and costs of nephroureterectomies in the management of upper tract urothelial carcinoma: a 10-year population-based analysis. BJU Int 2016;117:954-60.

35. Cowan NC. CT urography for hematuria. Nat Rev Urol 2012;9:218-26.

36. Brien JC, Shariat SF, Herman MP, et al. Preoperative hydronephrosis, ureteroscopic biopsy grade and urinary cytology can improve prediction of advanced upper tract urothelial carcinoma. J Urol 2010;184:69-73.

37. Ng CK, Shariat SF, Lucas SM, et al. Does the presence of hydronephrosis on preoperative axial CT imaging predict worse outcomes for patients undergoing nephroureterectomy for upper-tract urothelial carcinoma? Urol Oncol 2011;29:27-32. 